\title{
MicroRNA 433 regulates nonsense-mediated mRNA decay by targeting SMG5 mRNA
}

Yi Jin ${ }^{1,2+}$, Fang Zhang ${ }^{1 \dagger}$, Zhenfa Ma ${ }^{1}$ and Zhuqing Ren ${ }^{1,2^{*}}$

\begin{abstract}
Background: Nonsense-mediated mRNA decay (NMD) is a RNA quality surveillance system for eukaryotes. It prevents cells from generating deleterious truncated proteins by degrading abnormal mRNAs that harbor premature termination codon (PTC). However, little is known about the molecular regulation mechanism underlying the inhibition of NMD by microRNAs.

Results: The present study demonstrated that miR-433 was involved in NMD pathway via negatively regulating $S M G 5$. We provided evidence that (1) overexpression of miR-433 significantly suppressed the expression of SMG5 $(P<0.05)$; (2) Both mRNA and protein expression levels of TBL2 and GADD45B, substrates of NMD, were increased when SMG5 was suppressed by siRNA; (3) Expression of SMG5, TBL2 and GADD45B were significantly increased by miR433 inhibitor $(P<0.05)$. These results together illustrated that miR-433 regulated NMD by targeting SMG5 mRNA.

Conclusions: Our study highlights that miR-433 represses nonsense mediated mRNA decay. The miR-433 targets 3'-UTR of SMG5 and represses the expression of SMG5, whereas NMD activity is decreased when SMG5 is decreased. This discovery provides evidence for microRNA/NMD regulatory mechanism.
\end{abstract}

Keywords: miR-433, SMG5, NMD

\section{Background}

Nonsense-mediated mRNA decay (NMD) recognizes and degrades mRNAs that contain premature termination codon (PTC). This surveillance mechanism could prevent from generating deleterious truncated proteins $[1,2]$. UPF1 is an essential factor for NMD, which can recognize abnormal translation termination, and activate NMD [3]. Previous studies have indicated that suppressor with morphogenetic effect on genitalia 5 (SMG5) was involved in de-phosphorylation of UPF1 [4, 5]. SMG5 and 7 shared a conserved 14-3-3 like domain that could recognize the phosphorylated UPF1 [6]. When UPF1 was de-phosphorylated, SMG5 and 7 were recruited to

\footnotetext{
*Correspondence: renzq@mail.hzau.edu.cn

${ }^{\dagger} Y i$ Jin and Fang Zhang contributed equally to this work

${ }^{2}$ The Cooperative Innovation Center for Sustainable Pig Production,

Huazhong Agricultural University, Wuhan 430070, Hubei, People's

Republic of China

Full list of author information is available at the end of the article
}

the P-bodies [7]. Phosphorylated serine 1096 of UPF1 could bind the heterodimer formed by SMG5-7 [8]. In addition this heterodimer cold increase affinity combining to UPF1 [9]. SMG5-7 and protein phosphatase 2A (PP2A) plays an important role in the recycling for UPF1 $[10,11]$. Furthermore, SMG5-7 interacts with deadenylases CCR4-NOT complex [12], and SMG5 was associated to the decapping enhancer Prorich nuclear receptor co-activator 2 (PNRC2) recruiting the general decapping complex [13]. As the consequence, it is very important to investigate the expression and regulation of SMG5 for further understanding of NMD. One recent study indicated that DEAD box protein Ddx5 regulated SMG5 expression [14]. However, few studies have reported that microRNAs could regulate SMG5 expression. Here we demonstrated that a microRNA, miR-433, regulated SMG5 expression. Shih et al indicated that miR-433 was associated to poorer survival in ovarian cancer [15]. MiR433 expression was altered in gastric cancer [16], lung 
dysplasia and myeloproliferative neoplasms $[17,18]$. MiR-433 could also regulate the expression of SFRP2, GRB2, CREB1, and HDAC6, all of which were closely associated to cancer [19-23].

Two recent studies reported that miR-128, miR-125a, and miR-125b regulated NMD through silencing UPF1 and SMG1 [24, 25]. In present study, we demonstrated that miR-433 repressed the expression of SMG5, thereby suppressed NMD activity. Additionally, there may be a miR-433/NMD regulatory circuit in eukaryotic cells.

\section{Results}

\section{MiRNA-433 targets $3^{\prime}$-UTR of SMG5}

We selected the possible miRNAs targeting SMG5 through miRNA algorithm TargetScan (http://www. targetscan.org/), miRanda (http://www.microrna.org/ microrna/home.do), RNAhydrid (http://www.bibiserv. techfak.uni-bielefeld.de/rnahybrid/), and FINDTAR (http://www.bio.sz.tsinghua.edu.cn/). The prediction of all the softwares indicates that miR-433 targets SMG5 (Fig. 1a). The $3^{\prime}$-UTR of SMG5 holds a sequence motif (AUCAUGA) that is identical to the seed sequence UAGUACU (UAGUACU) of miR-433 (Fig. 1a). We performed the dual-luciferase assay to investigate miR-433 targeting SMG5. The wild report gene vector pmirGLO-SMG5WT and miR-433 mimic were co-transfected into HEK293T cells. Then we detected the normalized luciferase values, which showed $50 \%$ reduction compared with controls $(\mathrm{P}<0.01$, Fig. $1 \mathrm{~b})$. However, this regulation was abrogated when a four-nucleotide mutation (AUGAUACU) was introduced in the miR-433 seed sequence in the $3^{\prime}$-UTR of SMG5 (Fig. 1b). Additionally, the expression level of luciferase in SMG5 mutant was increased compared to SMG5 WT in the presence of NC (Fig. 1d). Furthermore, the dual-luciferase vectors and miR-433 inhibitor were co-transfected into Hela cells. The result showed SMG5 expression was increased (Fig. 1c). This regulation was also abrogated when the pmirGLOSMG5-MUT was transfected (Fig. 1c). In general, the results together showed that miR-433 targets $3^{\prime}$-UTR of SMG5 directly.

\section{The suppression of SMG5 repressed NMD activity}

The previous studies have indicated that SMG5 was an important NMD factor, so we are going to suppresse SMG5 expression by RNAi to confirm this function. The siRNA was transfected into $\mathrm{C} 2 \mathrm{C} 12$ cells for $24-48 \mathrm{~h}$. The results showed that SMG5 was decreased in both mRNA and protein expression level (Fig. 2a, b). According to the NMD mechanism, if NMD activity reduced, the expression of NMD substrates would be reduced. The NMD activity thereby was indicated by the expression level of NMD substrates, TBL2 and GADD45B. We detected the

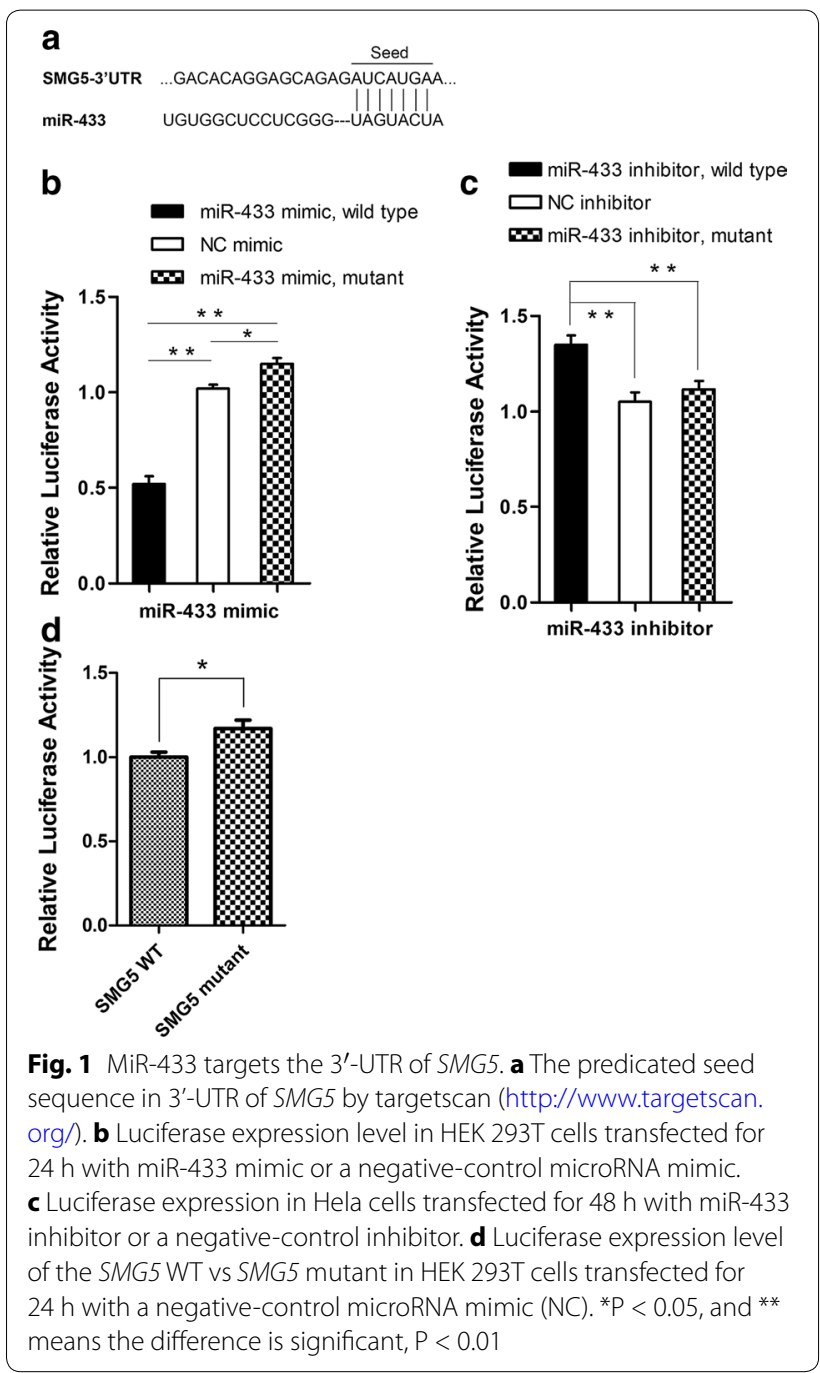

expression level of TBL2 and GADD45 and found that both of them were increased $(\mathrm{P}<0.05$, Fig. $2 \mathrm{c}-\mathrm{f})$. Therefore the RNAi experiment indicated that suppression of SMG5 repressed NMD activity.

\section{MiR-433 repressed SMG5 expression}

When we transfected miR-433 mimic into BHK cells, the expression level of SMG5 was decreased, $(\mathrm{P}<0.01$, Fig. 3). Furthermore, the expression level of SMG5 was increased significantly when the miR-433 inhibitor was transfected into the BHK cells $(\mathrm{P}<0.01$, Fig. 3$)$. As the consequence, the SMG5 expression was down-regulated by $\mathrm{miR}-433$.

\section{MiR-433 repressed NMD activity}

Since we have demonstrated that miR-433 repressed SMG5 expression and suppression of SMG5 repressed NMD activity, miR-433 would repress NMD activity. In 


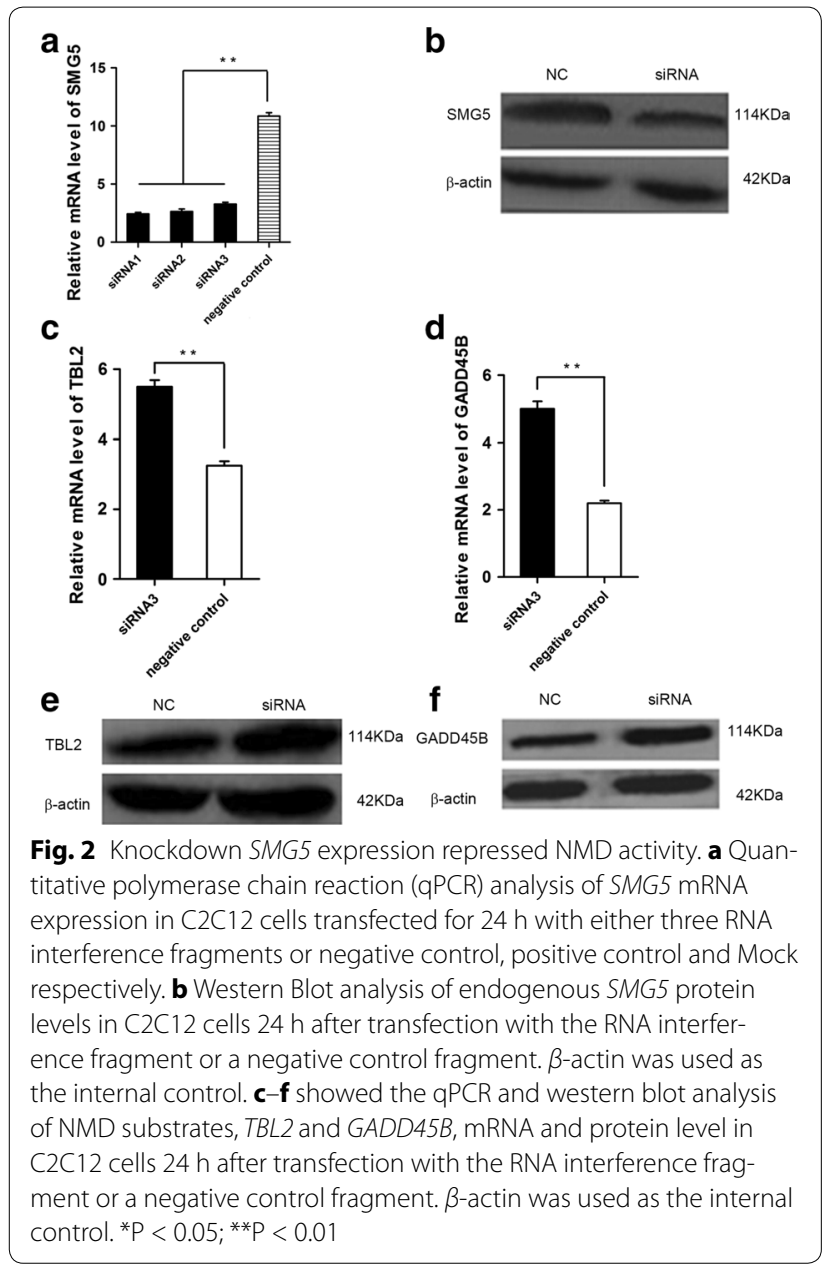

this section, the results showed that the NMD substrates TBL2 and GADD45B were increased in BHK cells when transfected with miR-433 mimic $(\mathrm{P}<0.05$, Fig. 4). In addition, we chose another cell line $(\mathrm{C} 2 \mathrm{C} 12)$ to transfect miR433 inhibitor. The expression level of TBL2 and GADD45B were also decreased by miR-433 inhibitor $(\mathrm{P}<0.05$, Fig. 4).

\section{Discussion}

Nonsense-mediated mRNA decay, a surveillance system, which recognizes mRNAs with translation termination codons positioned in abnormal contexts and degrades aberrant mRNAs, scrutinizes mRNA quality in all mammalian cells [26]. In this intricate process, a set of NMD factors are influential to the recognition and degradation of aberrant mRNAs. UPF1, the master regulator of NMD, is considered to determine the NMD process [27-29]. The ATPase and helicase activities as well as the phosphorylation of $\mathrm{N}$ - and $\mathrm{C}$ - terminal domains bestow on UPF1 ability that recognizes premature termination codon containing mRNAs selectively [30-33]. The phosphorylation and de-phosphorylation of UPF1 were

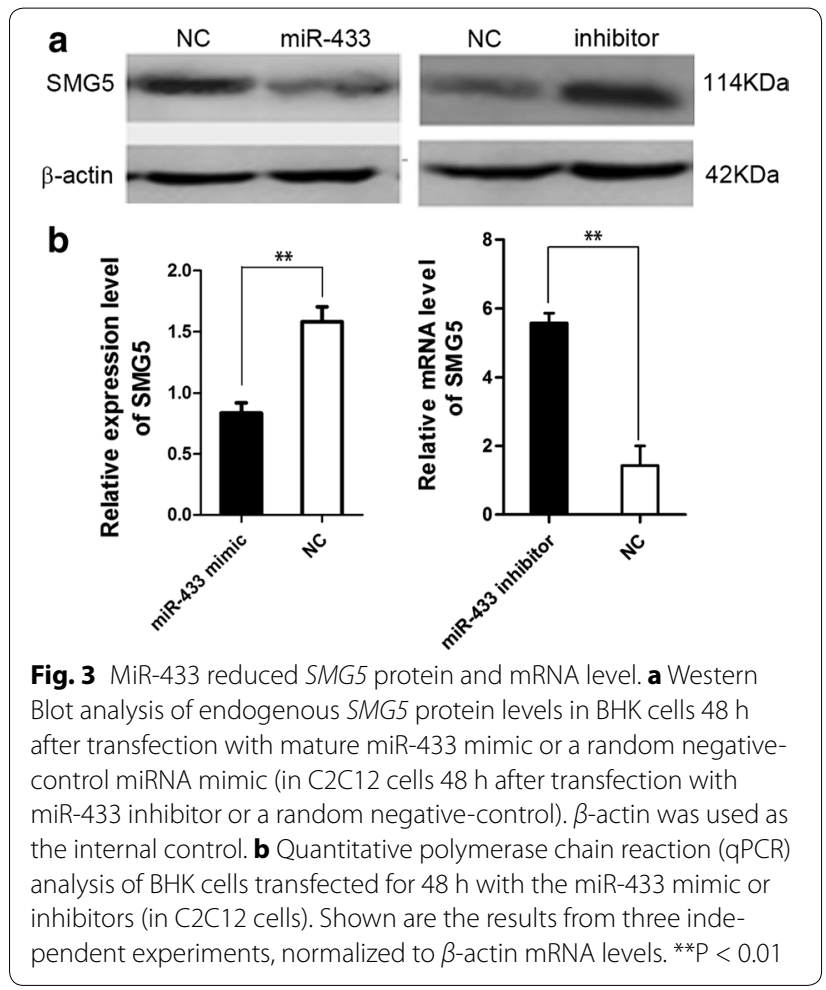

very important for NMD. SMG5, an important NMD factor, played an important role in UPF1 de-phosphorylation process. As our results showed, NMD activity was repressed when the expression of SMG5 was suppressed. So the regulation for SMG5 could affect NMD activity. We selected a microRNA, miR-433, which targets $3^{\prime}$-UTR of SMG5 by prediction. The regulation of miR-433 targeted SMG5 was detected by dual-luciferase report assay. The result indicated that SMG5 expression was reduced by $50 \%$ when we transfected with miR- 433 mimic. It has demonstrated that the NMD activity was repressed when SMG5 was suppressed (Fig. 3). Hence, miRNA-433 repressed NMD activity by suppressing SMG5 expression.

As a conserved mRNA surveillance system in eukaryotic cells, NMD is crucial for many physiological processes, and these crucial function of NMD have been published by many researches. Numbers of NMD factors were important for embryo development. When UPF1, UPF2, SMG1 or SMG6 was knockout or knockdown technologically, all mice died during an early embryonic stage [34-37]. A study implied that NMD has the potency that affects cell type diversification [34]. NMD activity was identified to be reduced in neuronal stem cells differentiation process. And this regulation of NMD activity is essential for nervous system development [38]. Additionally, NMD also regulates neural 


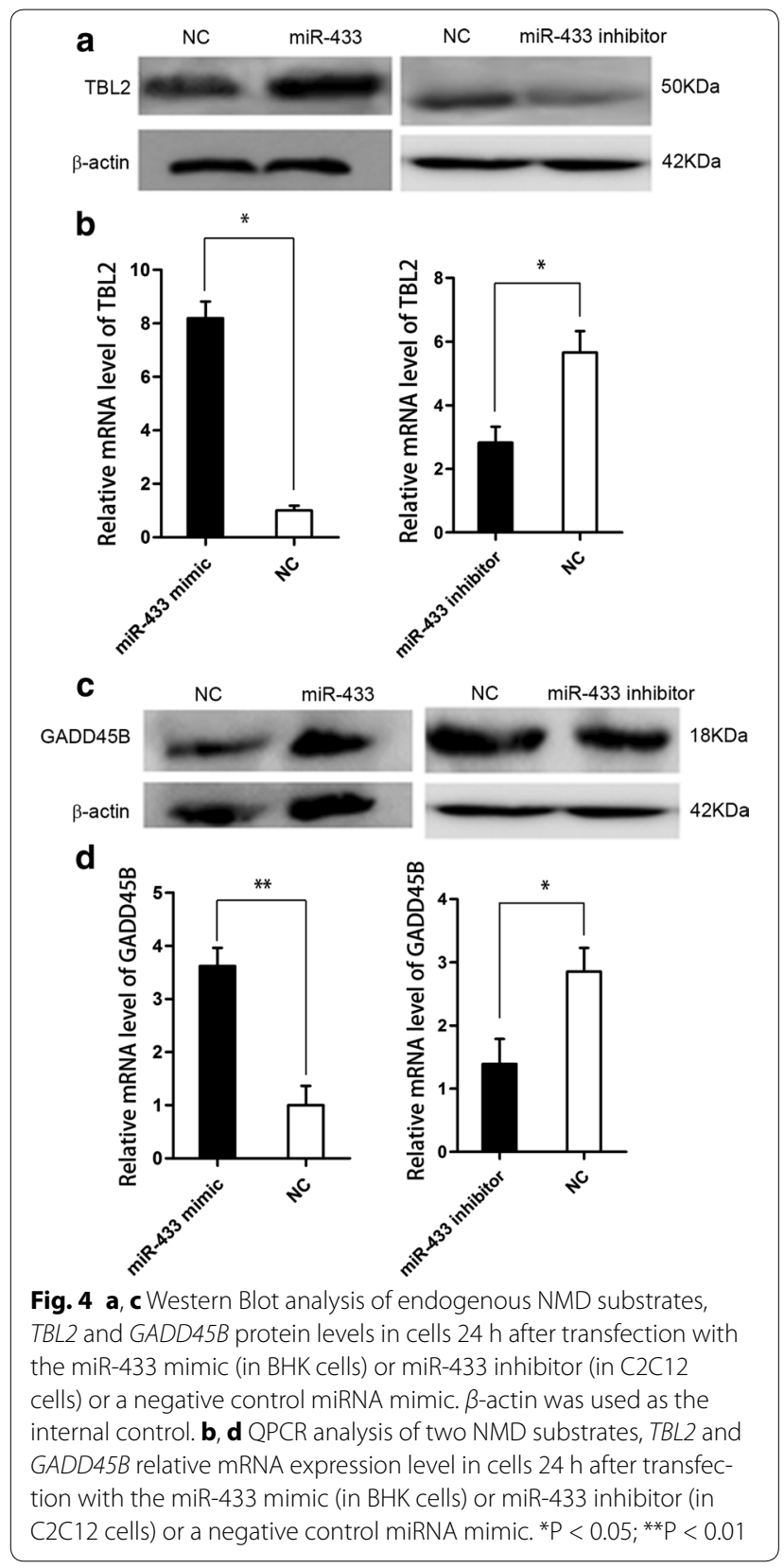

development related genes $[39,40]$. Here, our experiment indicated that miR-433 repressed SMG5 expression, and therefore suppressed NMD activity. This result indicated a circuit regulation of miR-433 and NMD. Hence, miR-433 could participate in the process regulated by NMD. For the circuit regulation, previous study identified miR-128 repressed NMD by UPF1 and MLN51 [24]. MiR-125 and 128 were involved in many nervous system disorder diseases such as autism [41], prion-induced neuron degeneration [42], Huntington's disease [43], Parkinson's disease [44], as well as Alzheimer's disease [45]. Some studies indicated that NMD played an important role in brain development and embryonic development [46, 47], and three essential embryonic brain vesicles formation disrupted by knockout of SMG1 [48]. Therefore, we assumed that there may be a miR-433/NMD regulatory circuit in early embryo development, especially in early nervous and brain development. This study would provide evidence to make clear the microRNA/NMD regulatory mechanism and give advice to neurological disease and related cancers therapies.

\section{Conclusion}

It is well known that nonsense mediated mRNA decay is an important mRNA quality surveillance system. However, the microRNA/NMD regulatory mechanism is not fully clear. Our study claim that NMD activity is repressed by a microRNA, miR-433. The miR-433 targets 3'UTR of SMG5 and decreases the expression of SMG5. NMD activity is suppressed when expression of SMG5 is reduced. This discovery provides evidence for microRNA/NMD regulatory mechanism and therapeutic advice for NMD-related diseases.

\section{Methods}

\section{Cell culture}

The cell lines, HEK-293T, Hela, BHK-21, and C2C12, were purchased from China for type culture collection (CCTCC). Cells expect for Hela were maintained in Dulbecco's modified Eagle's medium (DMEM, Hyclone, Logan, Utah, USA) supplemented with $10 \%$ fetal bovine serum (FBS, Hyclone, Logan, Utah, USA) at $37{ }^{\circ} \mathrm{C}$ in a humidified atmosphere of $5 \% \mathrm{CO}_{2}$. Hela cells were maintained in DMEM (Hyclone, Logan, Utah, USA) containing $20 \%$ FBS (Hyclone, Logan, Utah, USA) at $37{ }^{\circ} \mathrm{C}$ in a humidified atmosphere of $5 \% \mathrm{CO}_{2}$. Medium was changed twice weekly until the fibroblasts migrated out to cover the dishes. Passage 6-9 cells were used for all experiments.

\section{Isolation of 3'-UTR sequences of SMG5}

$\mathrm{C} 2 \mathrm{C} 12$ genome DNA was used as template to amplify $3^{\prime}$-UTR of SMG5. To isolate the 464-bp 3'-UTR of 2.6-kb genome, the following primer pairs were used: SMG5-3'UTR-F and SMG5-3'UTR-R [5'-cgagctcCTG TACTGGATAAGGGGTGCC-3' and $5^{\prime}$-ccgctcgagCA ACTGTTCCCTGGTTTTCCC, with uppercase bases corresponding to the mouse 2.6-kb SMG5 genome and lowercase bases indicating $5^{\prime}$ extensions with restriction enzyme sites (underline) for $\mathrm{SacI}$ and $\mathrm{XhoI}$, respectively]. The protocol was as follows: pre-denaturation at $94{ }^{\circ} \mathrm{C}$ for $2 \mathrm{~min}$, denaturation at $94{ }^{\circ} \mathrm{C}$ for $30 \mathrm{~s}$, annealing at $64{ }^{\circ} \mathrm{C}$ for $30 \mathrm{~s}$, elongation at $72{ }^{\circ} \mathrm{C}$ for $30 \mathrm{~s}$ per $1 \mathrm{~kb}$, thirty-five cycles, elongation at $72{ }^{\circ} \mathrm{C}$ for $2 \mathrm{~min}$, and end. 
PCR products were investigated by $1-2 \%$ agarose gel electrophoresis. The restriction enzyme, SacI and XhoI were purchased from Fermentas (Thermo Fisher Scientific, Rockford, IL, USA).

\section{Wild type report gene constructs}

The 2.2. PCR product was purified and cloned into the $\mathrm{SacI}$ and $\mathrm{XhoI}$ sites of pmirGLO dual-luciferase miRNA target expression vector (Promega, Madison, WI, USA). The enzyme digestion system contained $10 \times$ buffer $4 \mu \mathrm{L}$, SacI $4 \mu \mathrm{L}$, XhoI $4 \mu \mathrm{L}$, pmirGLO vector $12 \mu \mathrm{L}$, and the $\mathrm{ddH}_{2} \mathrm{O}$ up to $40 \mu \mathrm{L}$. The enzyme digestion system was incubated at $37{ }^{\circ} \mathrm{C}$ for $2 \mathrm{~h}$. The $\mathrm{T}_{4}$ DNA ligase (TaKaRa) interaction system contained enzyme digestion fragment $3 \mu \mathrm{L}$, digested pmirGLO plasmid $2 \mu \mathrm{L}$, Solution I $5 \mu \mathrm{L}$. The system was incubated at $16{ }^{\circ} \mathrm{C}$ for $2 \mathrm{~h}$. The accuracy of inserted $3^{\prime}$-UTR of SMG5 were confirmed by sequencing. Then the plasmid was isolated and purified using E.Z.N.A. ${ }^{\circledR}$ endo-free plasmid mini kit II (OMEGA, Bio-Tek, Norcross, GA, USA). The constructed wild type report gene recombinants named pmirGLO-SMG5-WT was stored at $-20^{\circ} \mathrm{C}$.

\section{Introducing four-nucleotide mutagenesis into SMG5 3'-UTR}

Two primer pairs, SMG5-3'UTR-F (5'-cgagctcCTGTA CTGGATAAGGGGTGCC-3') and SMG5-3'UTR-R ( $5^{\prime}$ - ccgctcgag CAACTGT TCCCTGGT TT TCCC), SMG5-3'UTR-MF (5'-AGCAGAGATCTACTATACTC AG-3') and SMG5-3'UTR-MR (5'-GCCCCTGAGT ATAGTAGATCTCTG-3'), were designed (uppercase bases corresponding to the mouse 2.6-kb SMG5 genome and lowercase bases indicating $5^{\prime}$ extensions with restriction enzyme sites [underline] for $\mathrm{SacI}$ and $\mathrm{XhoI}$, respectively. And the bold bases mean four-nucleotide mutation sites of SMG5 3'-UTR). The former was used to construct pmirGLO-SMG5-WT, whereas the latter to amplify the mutation sites and its upstream sequence (production I), and the mutation sites and its downstream sequence (production II) respectively, the pmirGLO-SMG5-WT plasmid was the template. Then using fusion PCR combined these two products. The PCR system contained $2 \times$ taq PCR mix $11 \mu \mathrm{L}$, recovered production I $2 \mu \mathrm{L}$, recovered production II $2 \mu \mathrm{L}, \mathrm{dd}_{2} \mathrm{O} 10 \mu \mathrm{L}$. PCR conditions: an initial denaturation at $95^{\circ} \mathrm{C}$ for $4 \mathrm{~min}$, followed by 30 cycles of $95^{\circ} \mathrm{C}$ for $30 \mathrm{~s}, 40^{\circ} \mathrm{C}$ for $30 \mathrm{~s}, 45^{\circ} \mathrm{C}$ for $5 \mathrm{~s}$, $50{ }^{\circ} \mathrm{C}$ for $5 \mathrm{~s}, 55^{\circ} \mathrm{C}$ for $5 \mathrm{~s}, 60^{\circ} \mathrm{C}$ for $5 \mathrm{~s}$ and $72^{\circ} \mathrm{C}$ for $30 \mathrm{~s}$, with a final extension of $5 \mathrm{~min}$ at $72{ }^{\circ} \mathrm{C}$. PCR products were visible after electrophoresis of $25-\mu \mathrm{L}$ reaction using an agarose gel $(1.5 \%)$. Then the fusion PCR production was recovered and used as a template.

\section{Mutant report gene constructs}

The 464 bp mutant SMG5 3'-UTR was amplified, purified, and cloned into the $S a c$ I and XhoI sites of pmirGLO dual-luciferase miRNA target expression vector (Promega, Madison, WI). The enzyme digestion system contained $10 \times$ buffer $4 \mu \mathrm{L}$, SacI $4 \mu \mathrm{L}, \mathrm{XhoI} 4 \mu \mathrm{L}$, pmirGLO vector $12 \mu \mathrm{L}$, and $\mathrm{ddH}_{2} \mathrm{O}$ up to $40 \mu \mathrm{L}$. The enzyme digestion system was incubated at $37^{\circ} \mathrm{C}$ for $2 \mathrm{~h}$. The $\mathrm{T}_{4}$ DNA ligase $(\mathrm{TaKaRa})$ interaction system contained enzyme digestion fragment $3 \mu \mathrm{L}$, digested pmirGLO plasmid $2 \mu \mathrm{L}$, Solution I $5 \mu \mathrm{L}$. This system was incubated at $16{ }^{\circ} \mathrm{C}$ for $2 \mathrm{~h}$. The accuracy of inserted SMG5 $3^{\prime}$-UTR was confirmed by sequencing. Then the plasmid was isolated and purified using E.Z.N.A. ${ }^{\circledR}$ endo-free plasmid mini kit II (OMEGA, Bio-Tek, Norcross, GA, USA). The mutant report gene vector,named pmirGLO-SMG5-MUT conserved at $-20^{\circ} \mathrm{C}$.

\section{Cell transfection and dual-luciferase assay}

HEK-293T cells were seeded onto 24-well plates at $30-40 \%$ confluence. The next day, medium was changed to Opti-MEM I Reduced Serum Medium (Hyclone, Logan, Utah, USA), and cells were transfected with pmirGLO-SMG5-WT constructs (200 ng per well). After 4-6 h, medium was replaced by MEM containing 10 \% FBS (Hyclone, Logan, Utah, USA). Transfected cells were washed twice with cold PBS (Hyclone, Logan, Utah, USA), lysed using $1 \times$ passive lysis buffer (Promega) for $30 \mathrm{~min}$, and assayed for firefly and Renilla luciferase activities by the dual-luciferase assay (Promega) in a PerkimELmer 2030 Microplate Reader (Lenovo, China) according to the manufacturer's instructions. At least three independent experiments were performed for each assay, each time with a minimum of $n=4$. For co-transfection, cells were grown on 24-well plates. For each well, a transfection mixture $(200 \mu \mathrm{L})$ consisting of $0.2-\mu \mathrm{g}$ reporter construct, $1.25 \mu \mathrm{L}$ miR-433 mimic or negative control, and $2 \mu \mathrm{L}$ Lipofectamine 2000 Reagent (Invitrogen) was prepared. Opti-MEM I Reduced Serum Medium was used as diluent. Hella cells were treated as same as the HEK-293T, but the medium was MEM containing $20 \%$ FBS.

\section{RNA isolation and mRNA/miRNA quantitation}

The RNA isolation reagent was TRizol ${ }^{\circledR}$ Reagent (Invitrogen, Carlsbad, CA, USA). RNA was quantified spectroscopically (ND-1000 Spectrophotometer; NanoDrop, Wilmington, DE, USA), and integrity was assessed by agarose gel electrophoresis. According to the manufacturer's protocol, RNA was reverse-transcribed using RNA PCR kit (Takara Bio Inc.). The gene expression was 
investigated by RT-PCR. Primers for RT-PCR were as follows: SMG5-qF (5'-TACCTCATCCCTGACACCCA- $3^{\prime}$ ) and SMG5-qR (5'-GCCCCTGGCTGTTCTTTCT-3'), miR-433-qF (CTGGTAGGATCATGATGGGAT) and miR-433-qR (TCAACTGGTGTCGTGGAGT), U6-qF (CTGGTAGGGTGCTCGCTTCGGCAG) and U6-qR (CAACTGGTGTCGTGGAGTCGGC), TBL2-qF (5'-AA GTATCTGGCCACCTGTGC-3') and TBL2-qR (5'-GG CCAGCCAAACAATGAAGG-3'), GADD45B-qF (5'-AA GGCGGCCAAACTGATGAAT- $3^{\prime}$ ) and GADD45B-qR (5'-ATTGTCGCAGCAGAACGACT- $\left.3^{\prime}\right), \beta$-actin-F ( $5^{\prime}$-G CCTCACTGTCCACCTTCCA- $\left.3^{\prime}\right)$ and $\beta$-actin-R ( $5^{\prime}-\mathrm{A}$ GCCATGCCAATGTTGTCTCTT- $3^{\prime}$ ). All the primer pairs for each gene were used for gene-specific amplification. The expression of $\beta$-actin was the internal control. For quantification, the comparative threshold cycle method was used to assess relative changes in mRNA levels [49].

\section{MicroRNA overexpression assay}

MiR-433 mimic and inhibitor were purchased from GenePharma (shanghai, China). MiR-433 mimic could enhance endogenous miR-433 function, and miR-433 inhibitor could repress the endogenous miR-433 function. HK-21 cells and $\mathrm{C} 2 \mathrm{C} 12$ cells were seeded onto 6-well plates in DMEM supplemented with $10 \% \mathrm{FBS}$ at $37{ }^{\circ} \mathrm{C}$ in a humidified atmosphere of $5 \% \mathrm{CO}_{2}$. The next day, when the cells confluence get 70-80\%, the medium was changed to Opti-MEM I Reduced Serum Medium (Hyclone, Logan, Utah, USA), and cells were transfected with $10 \mu \mathrm{L}$ miRNA mimic $(0.02 \mathrm{nmol} / \mu \mathrm{L})$ using Lipofectamine 2000 Reagent (Invitrogen). After 4-6 h, medium was replaced by MEM containing $10 \%$ FBS (Hyclone, Logan, Utah, USA). Transfected cells were washed twice with cold PBS (Hyclone, Logan, Utah, USA). At least three independent experiments were performed for each assay, each time with a minimum of $\mathrm{n}=4$. Opti-MEM I Reduced Serum Medium was used as diluent. The mimic was added fluorescent tag so that it could be detected under fluorescence microscope to calculate the transfection efficiency.

\section{Small interfering RNA design and cell transfection}

The musSMG5 mRNA sequence and internal control $(\beta$-actin) mRNA sequences were obtained from NCBI database (http://www.ncbi.nlm.nih.gov/). The siRNAs were purchased from Genpharma (Inc. Shanghai, China). The sequences if siRNAs were as follows: siRNA1 5'-GCCGCUUCAUCAUCAUCAUTT-3' for sense and $5^{\prime}$-AUGAUGAUGAUGAAGCGGCTT- ${ }^{\prime}$ for antisense; siRNA2 $5^{\prime}$-GGAGUGUGAAAGUGGAUAU TT-3' for sense and 5'-AUAUCCACUUUCACACU CCTT-3' ${ }^{\prime}$ for antisense; siRNA3 $5^{\prime}$-GCAGGCAGCAA
GUAUUACATT-3' for sense and 5'-UGUAAUACUU GCUGCCUGCTT-3' for antisense; NC (negative control) $5^{\prime}$-UUCUCCGAACGUGUCACGUTT-3' for sense and $5^{\prime}$-ACGUGACACGUUCGGAGAATT-3' for antisense. $\mathrm{C} 2 \mathrm{C} 12$ cells were incubated in $5 \% \mathrm{CO} 2$ at $37{ }^{\circ} \mathrm{C}$ in DMEM (Hyclone, Logan, Utah, USA) supplemented with 10 \% FBS (Hyclone, Logan, Utah, USA). One day before transfection, $10^{5}$ cells were plated in $2 \mathrm{~mL}$ DMEM containing $10 \%$ FBS per well of a 6-well plate. The next day, when the cells confluence get $50 \%$, the medium was changed to Opti-MEM I Reduced Serum Medium (Hyclone, Logan, Utah, USA), and cells were transfected with $10 \mu \mathrm{L}$ siRNA using $10 \mu \mathrm{L}$ Lipofectamine 2000 Reagent (Invitrogen). After 4-6 h, medium was replaced by MEM containing 10 \% FBS (Hyclone, Logan, Utah, USA). The cells were incubated for 24-48 h. Transfected cells were washed twice with cold PBS (Hyclone, Logan, Utah, USA). At least three independent experiments were performed for each assay, each time with a minimum of $\mathrm{n}=4$. Opti-MEM I Reduced Serum Medium was used as diluent.

\section{Western blotting}

The whole-cell protein of BHK-21 and $\mathrm{C} 2 \mathrm{C} 12$ were collected using RIPA and PMSF, and conserved at $-20{ }^{\circ} \mathrm{C}$. The concentration of protein was detected using the bicinchoninic acid (BCA) method (Beyotime Biotechnology, Jiangsu, China). Subsequently, samples were separated by SDS-PAGE (10 \%) and electroblotted onto polyvinylidene fluoride (PVDF) membrane (Millipore, USA). Membrane was blocked with $1 \times$ TBST supplemented with $5 \%$ skimmed milk powder (servicebio, Wuhan, China). Membranes were incubated with the primary antibody, anti-SMG5 (P-14) (goat. \#SC50980, Santa Cruz Biotechnology, Inc.). For normalization of the results, membranes were reblotted for $\beta$-actin (anti$\beta$-actin, servicebio, Wuhan). Proteins were detected with secondary antibody (HRP-rabbit, anti-goat, 1:1000; boster, Wuhan, China). For the TBL2 and GADD45B western blotting analysis, the primary antibodies were anti-TBL2 (L-15) (goat. \#SC-104692, Santa Cruz Biotechnology, Inc.), and anti-GADD45B (rabbit, \#ab128920, abcam, Inc.). Bands on the X-ray films were quantified with WCIF ImageJ software for the densitometry analysis.

\section{Statistical analysis}

All data were displayed as the mean \pm SD of three independent experiments, in which each assay was performed in triplicate. Statistically significant differences between two groups were determined by Student's $\mathrm{t}$ test. $\mathrm{P}<0.05$ was considered statistically significant. 


\section{Abbreviations}

miR-433: microRNA-433; NMD: nonsense mediated mRNA decay; SMG5: suppressor with morphological effect on genitalia 5; PTC: premature termination codon; TBL2: transducin beta-like protein 2; GADD45B: growth arrest and DNA damage-inducible protein GADD45 beta; UTR: untranslated regions; UPF1: up-framshift 1; SMG7: suppressor with morphological effect on genitalia 7; PP2A: protein phosphatase 2A; PNRC2: prorich nuclear receptor co-activator 2; SFRP2: secreted frizzled-related protein 2; GRB2: growth factor receptor-bound protein 2; CREB1: CAMP-response element binding protein; HDAC6: histone deacetylase 6

\section{Authors' contributions}

YJ sorted and analyzed data, wrote the article. FZ designed this experiment, and performed the experiment. ZM purchased the regents and materials for the experiment, and performed some part of the experiment. ZR designed this work and participated in the revision of this article. All authors read and approved the final manuscript.

\section{Author details}

1 Key Laboratory of Swine Genetics and Breeding of Ministry of Agriculture \& Key Laboratory of Agriculture Animal Genetics, Breeding and Reproduction of Ministry of Education, College of Animal Science, Huazhong Agricultural University, Wuhan 430070, Hubei, People's Republic of China. ${ }^{2}$ The Cooperative Innovation Center for Sustainable Pig Production, Huazhong Agricultural University, Wuhan 430070, Hubei, People's Republic of China.

\section{Acknowledgements}

None.

\section{Competing interests}

The authors declare that they have no competing interests.

\section{Availability of data and materials}

The original data of the real-time PCR experiments, dual-luciferase assay and data images for western blot analysis will be available upon request.

\section{Funding}

This work was supported by the Fundamental Research Funds for the Central Universities (No. 2662015PY103, No. 2013PY032), the Natural Science Foundation of Hubei Province of China (No. 2014CFB265) and the National Key Technology Support Program of China (No. 2015BAl09B06).

Received: 18 February 2016 Accepted: 23 July 2016

Published online: 29 July 2016

\section{References}

1. Nagy E, Maquat LE. A rule for termination-codon position within introncontaining genes: when nonsense affects RNA abundance. Trends Biochem Sci. 1998;23(6):198-9.

2. Peltz SW, Brown AH, Jacobson A. mRNA destabilization triggered by premature translational termination depends on at least three cisacting sequence elements and one trans-acting factor. Genes Dev. 1993;7(9):1737-54.

3. Hilleren P, Parker R. mRNA surveillance in eukaryotes: kinetic proofreading of proper translation termination as assessed by mRNP domain organization? RNA. 1999;5(6):711-9.

4. Chiu SY, Serin G, Ohara O, Maquat LE. Characterization of human Smg5/7a: a protein with similarities to Caenorhabditis elegans SMG5 and SMG7 that functions in the dephosphorylation of Upf1. RNA. 2003;9(1):77-87

5. Ohnishi T, Yamashita A, Kashima I, Schell T, Anders KR, Grimson A, Hachiya T, Hentze MW, Anderson P, Ohno S. Phosphorylation of hUPF1 induces formation of mRNA surveillance complexes containing hSMG-5 and hSMG-7. Mol Cell. 2003;12(5):1187-200.

6. Fukuhara N, Ebert J, Unterholzner L, Lindner D, Izaurralde E, Conti E. SMG7 is a 14-3-3-like adaptor in the nonsense-mediated mRNA decay pathway. Mol Cell. 2005;17(4):537-47.
7. Unterholzner L, Izaurralde E. SMG7 acts as a molecular link between mRNA surveillance and mRNA decay. Mol Cell. 2004;16(4):587-96.

8. Okada-Katsuhata Y, Yamashita A, Kutsuzawa K, Izumi N, Hirahara F, Ohno S. N- and C-terminal Upf1 phosphorylations create binding platforms for SMG-6 and SMG-5:SMG-7 during NMD. Nucleic Acids Res. 2012;40(3):1251-66.

9. Jonas $\mathrm{S}$, Weichenrieder $\mathrm{O}$, Izaurralde $\mathrm{E}$. An unusual arrangement of two 14-3-3-like domains in the SMG5-SMG7 heterodimer is required for efficient nonsense-mediated mRNA decay. Genes Dev. 2013;27(2):211-25.

10. Anders KR, Grimson A, Anderson P. SMG-5, required for C. elegans nonsense-mediated mRNA decay, associates with SMG-2 and protein phosphatase 2A. EMBO J. 2003;22(3):641-50.

11. Durand S, Cougot N, Mahuteau-Betzer F, Nguyen CH, Grierson DS, Bertrand E, Tazi J, Lejeune F. Inhibition of nonsense-mediated mRNA decay (NMD) by a new chemical molecule reveals the dynamic of NMD factors in P-bodies. J Cell Biol. 2007;178(7):1145-60.

12. Loh B, Jonas S, Izaurralde E. The SMG5-SMG7 heterodimer directly recruits the CCR4-NOT deadenylase complex to mRNAs containing nonsense codons via interaction with POP2. Genes Dev. 2013;27(19):2125-38.

13. Cho H, Han S, Choe J, Park SG, Choi SS, Kim YK. SMG5-PNRC2 is functionally dominant compared with SMG5-SMG7 in mammalian nonsensemediated mRNA decay. Nucleic Acids Res. 2013;41(2):1319-28.

14. Geissler V, Altmeyer S, Stein B, Uhlmann-Schiffler H, Stahl H. The RNA helicase Ddx5/p68 binds to hUpf3 and enhances NMD of Ddx17/p72 and Smg5 mRNA. Nucleic Acids Res. 2013;41(16):7875-88.

15. Shih KK, Qin LX, Tanner EJ, Zhou Q, Bisogna M, Dao F, Olvera N, Viale A, Barakat RR, Levine DA. A microRNA survival signature (MiSS) for advanced ovarian cancer. Gynecol Oncol. 2011;121(3):444-50.

16. Ueda T, Volinia S, Okumura H, Shimizu M, Taccioli C, Rossi S, Alder H, Liu CG, Oue N, Yasui W, et al. Relation between microRNA expression and progression and prognosis of gastric cancer: a microRNA expression analysis. Lancet Oncol. 2010;11(2):136-46.

17. Del Vescovo V, Meier T, Inga A, Denti MA, Borlak J. A cross-platform comparison of affymetrix and Agilent microarrays reveals discordant miRNA expression in lung tumors of c-Raf transgenic mice. PLoS ONE. 2013;8(11):e78870.

18. Lin X, Rice KL, Buzzai M, Hexner E, Costa FF, Kilpivaara O, Mullally A, Soares $M B$, Ebert BL, Levine R, et al. miR-433 is aberrantly expressed in myeloproliferative neoplasms and suppresses hematopoietic cell growth and differentiation. Leukemia. 2013;27(2):344-52.

19. Gotanda K, Hirota T, Matsumoto N, leiri I. MicroRNA-433 negatively regulates the expression of thymidylate synthase (TYMS) responsible for 5-fluorouracil sensitivity in HeLa cells. BMC Cancer. 2013;13:369.

20. Luo $H$, Zhang $H$, Zhang Z, Zhang X, Ning B, Guo J, Nie N, Liu B, Wu X. Down-regulated miR-9 and miR-433 in human gastric carcinoma. J Exp Clin Cancer Res. 2009;28:82.

21. Simon D, Laloo B, Barillot M, Barnetche T, Blanchard C, Rooryck C, Marche M, Burgelin I, Coupry I, Chassaing N, et al. A mutation in the $3^{\prime}$-UTR of the HDAC6 gene abolishing the post-transcriptional regulation mediated by hsa-miR-433 is linked to a new form of dominant X-linked chondrodysplasia. Hum Mol Genet. 2010;19(10):2015-27.

22. Snyder CM, Rice AL, Estrella NL, Held A, Kandarian SC, Naya FJ. MEF2A regulates the Gt12-Dio3 microRNA mega-cluster to modulate WNT signaling in skeletal muscle regeneration. Development. 2013;140(1):31-42.

23. Yang Z, Tsuchiya $H$, Zhang $Y$, Hartnett ME, Wang L. MicroRNA-433 inhibits liver cancer cell migration by repressing the protein expression and function of CAMP response element-binding protein. J Biol Chem. 2013;288(40):28893-9.

24. Bruno IG, Karam R, Huang LL, Bhardwaj A, Lou CH, Shum EY, Song HW, Corbett MA, Gifford WD, Gecz J, et al. Identification of a MicroRNA that activates gene expression by repressing nonsense-mediated RNA decay. Mol Cell. 2011;42(4):500-10.

25. Wang G, Jiang B, Jia C, Chai B, Liang A. MicroRNA 125 represses nonsensemediated mRNA decay by regulating SMG1 expression. Biochem Biophys Res Commun. 2013;435(1):16-20.

26. Lykke-Andersen SJT. Nonsense-mediated mRNA decay: an intricate machinery that shapes transcriptomes. Nat Rev Mol Cell Biol. 2015;16:665-7.

27. Kervestin S, Jacobson A. NMD: a multifaceted response to premature translational termination. Nat Rev Mol Cell Biol. 2012;13(11):700-12. 
28. Schweingruber C, Rufener SC, Zund D, Yamashita A, Muhlemann O. Nonsense-mediated mRNA decay - mechanisms of substrate mRNA recognition and degradation in mammalian cells. Biochim Biophys Acta. 2013;1829(6-7):612-23.

29. Siwaszek A, Ukleja M, Dziembowski A. Proteins involved in the degradation of cytoplasmic mRNA in the major eukaryotic model systems. RNA Biol. 2014;11(9):1122-36.

30. Franks TM, Singh G, Lykke-Andersen J. Upf1 ATPase-dependent mRNP disassembly is required for completion of nonsense-mediated mRNA decay. Cell. 2010;143(6):938-50.

31. Kashima I, Yamashita A, Izumi N, Kataoka N, Morishita R, Hoshino S, Ohno M, Dreyfuss G, Ohno S. Binding of a novel SMG-1-Upf1-eRF1-eRF3 complex (SURF) to the exon junction complex triggers Upf1 phosphorylation and nonsense-mediated mRNA decay. Genes Dev. 2006;20(3):355-67.

32. Kurosaki T, Li W, Hoque M, Popp MW, Ermolenko DN, Tian B, Maquat LE. A post-translational regulatory switch on UPF1 controls targeted mRNA degradation. Genes Dev. 2014;28(17):1900-16.

33. Weng Y, Czaplinski K, Peltz SW. Genetic and biochemical characterization of mutations in the ATPase and helicase regions of the Upf1 protein. Mol Cell Biol. 1996;16(10):5477-90.

34. Li T, Shi Y, Wang P, Guachalla LM, Sun B, Joerss T, Chen YS, Groth M, Krueger A, Platzer M, et al. Smg6/Est1 licenses embryonic stem cell differentiation via nonsense-mediated mRNA decay. EMBO J. 2015;34(12):1630-47.

35. Mcllwain DR, Pan Q, Reilly PT, Elia AJ, McCracken S, Wakeham AC, ItieYouten A, Blencowe BJ, Mak TW. Smg1 is required for embryogenesis and regulates diverse genes via alternative splicing coupled to nonsensemediated mRNA decay. Proc Natl Acad Sci USA. 2010;107(27):12186-91.

36. Medghalchi SM, Frischmeyer PA, Mendell JT, Kelly AG, Lawler AM, Dietz HC. Rent1, a trans-effector of nonsense-mediated mRNA decay, is essential for mammalian embryonic viability. Hum Mol Genet. 2001;10(2):99-105.

37. Weischenfeldt J, Damgaard I, Bryder D, Theilgaard-Monch K, Thoren LA, Nielsen FC, Jacobsen SE, Nerlov C, Porse BT. NMD is essential for hematopoietic stem and progenitor cells and for eliminating by-products of programmed DNA rearrangements. Genes Dev. 2008:22(10):1381-96.

38. Lou CH, Shao A, Shum EY, Espinoza JL, Huang L, Karam R, Wilkinson MF. Posttranscriptional control of the stem cell and neurogenic programs by the nonsense-mediated RNA decay pathway. Cell Rep. 2014;6(4):748-64.
39. Colak D, Ji SJ, Porse BT, Jaffrey SR. Regulation of axon guidance by compartmentalized nonsense-mediated mRNA decay. Cell. 2013;153(6):1252-65.

40. Nguyen LS, Jolly L, Shoubridge C, Chan WK, Huang L, Laumonnier F, Raynaud M, Hackett A, Field M, Rodriguez J, et al. Transcriptome profiling of UPF3B/NMD-deficient lymphoblastoid cells from patients with various forms of intellectual disability. Mol Psychiatry. 2012;17(11):1103-15.

41. Abu-Elneel K, Liu T, Gazzaniga FS, Nishimura Y, Wall DP, Geschwind DH, Lao K, Kosik KS. Heterogeneous dysregulation of microRNAs across the autism spectrum. Neurogenetics. 2008;9(3):153-61.

42. Saba R, Goodman CD, Huzarewich RL, Robertson C, Booth SA. A miRNA signature of prion induced neurodegeneration. PLoS ONE. 2008;3(11):e3652.

43. Lee ST, Chu K, Im WS, Yoon HJ, Im JY, Park JE, Park KH, Jung KH, Lee SK, Kim M, et al. Altered microRNA regulation in Huntington's disease models. Exp Neurol. 2011;227(1):172-9.

44. Kim J, Inoue K, Ishii J, Vanti WB, Voronov SV, Murchison E, Hannon G, Abeliovich A. A MicroRNA feedback circuit in midbrain dopamine neurons. Science. 2007;317(5842):1220-4

45. Lukiw WJ. Micro-RNA speciation in fetal, adult and Alzheimer's disease hippocampus. NeuroReport. 2007;18(3):297-300.

46. Wittkopp N, Huntzinger E, Weiler C, Sauliere J, Schmidt S, Sonawane M, Izaurralde E. Nonsense-mediated mRNA decay effectors are essential for zebrafish embryonic development and survival. Mol Cell Biol. 2009;29(13):3517-28

47. Anastasaki C, Longman D, Capper A, Patton EE, Caceres JF. Dhx34 and Nbas function in the NMD pathway and are required for embryonic development in zebrafish. Nucleic Acids Res. 2011;39(9):3686-94.

48. Mcllwain DR, Pan Q, Reilly PT, Elia AJ, McCracken S, Wakeham AC, ItieYouten A, Blencowe BJ, Mak TW. Smg1 is required for embryogenesis and regulates diverse genes via alternative splicing coupled to nonsensemediated mRNA decay. P Natl Acad Sci USA. 2010;107(27):12186-91.

49. Livak KJ, Schmittgen TD. Analysis of relative gene expression data using real-time quantitative PCR and the 2(-Delta Delta C(T)) method. Methods. 2001:25(4):402-8.

\section{Submit your next manuscript to BioMed Central and we will help you at every step:}

- We accept pre-submission inquiries

- Our selector tool helps you to find the most relevant journal

- We provide round the clock customer support

- Convenient online submission

- Thorough peer review

- Inclusion in PubMed and all major indexing services

- Maximum visibility for your research

Submit your manuscript at www.biomedcentral.com/submit 